\title{
Calibration of Accelerometers at the Dropball Station
}

\author{
F. N. Rebarchik \\ Sandia Calibration and Instrumentation Department \\ Sandia National Laboratories \\ Albuquerque, NM 87185-5800
}

\begin{abstract}
This memorandum is a synopsis of the description and operation of the equipment used and the events occurring during the calibration of various accelerometers at the Dropball Station.
\end{abstract}




\section{Acknowledgment}

The author acknowledges W. B. Leisher, 6643, for his comments. 


\section{Contents}

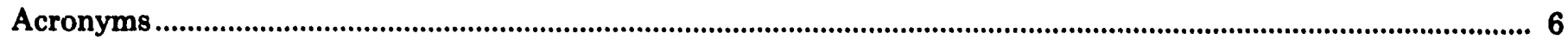

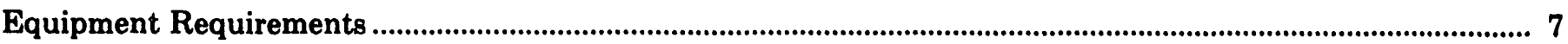

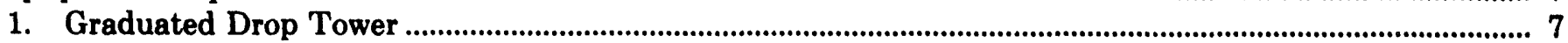

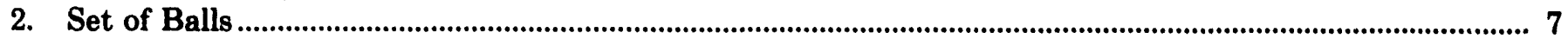

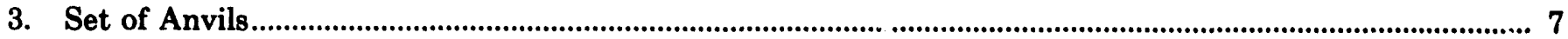

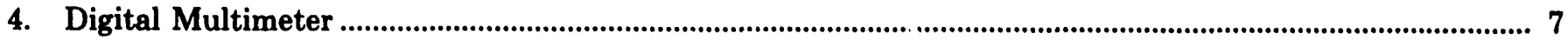

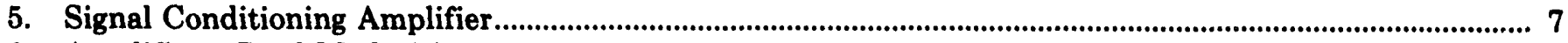

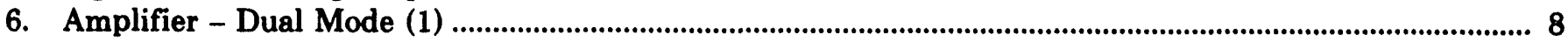

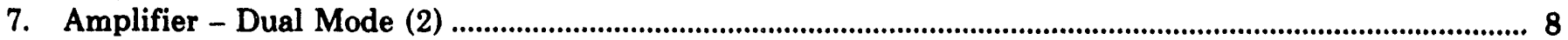

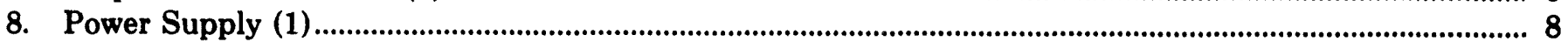

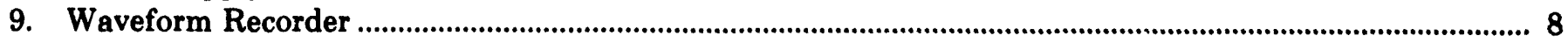

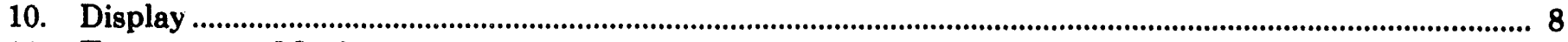

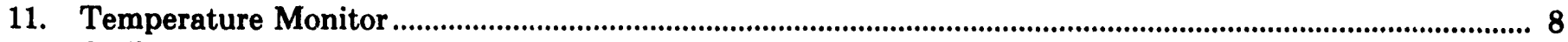

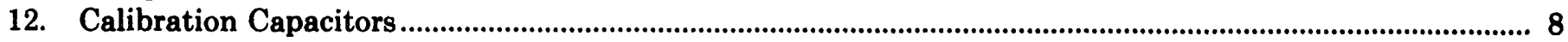

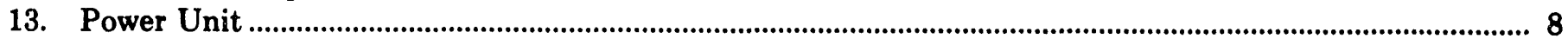

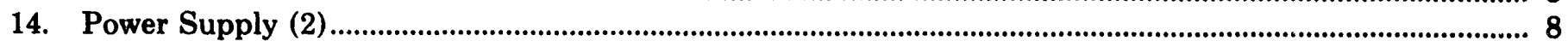

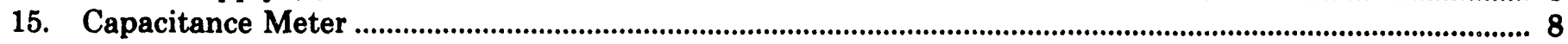

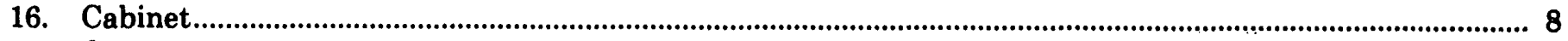

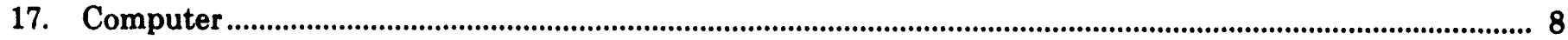

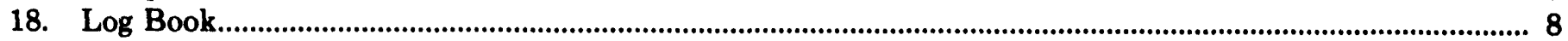

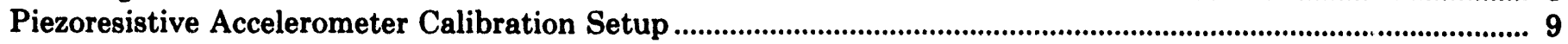

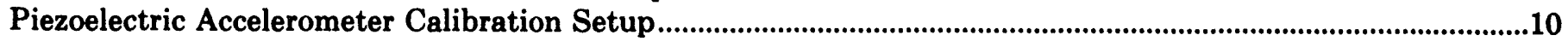

Notes, Hints, and "Tricks of the Trade" With the Dropball ......................................................................................11

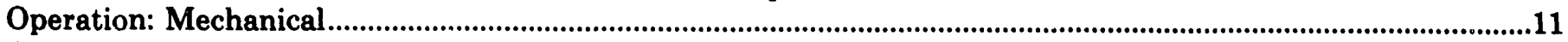

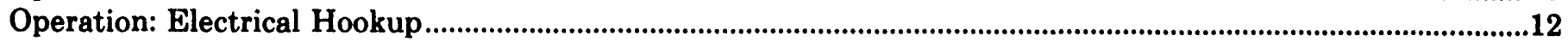

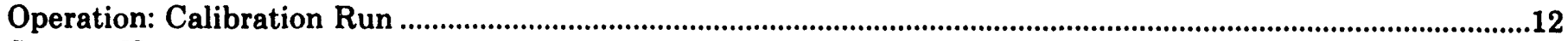

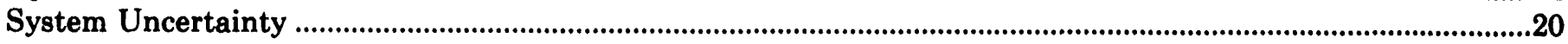

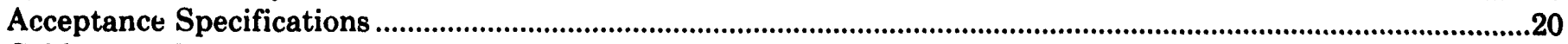

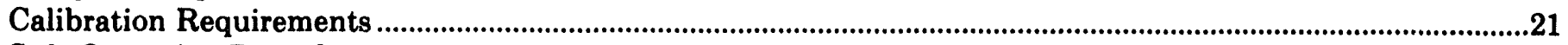

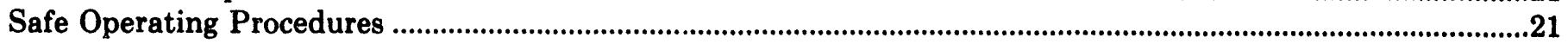

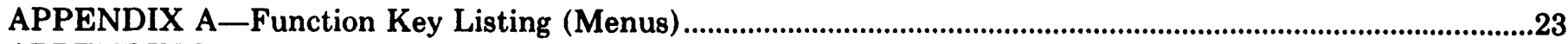

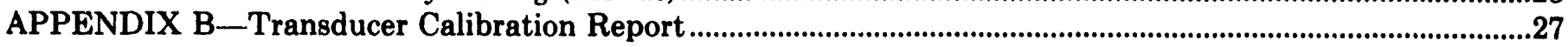

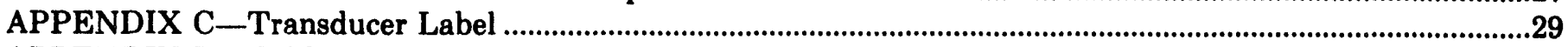

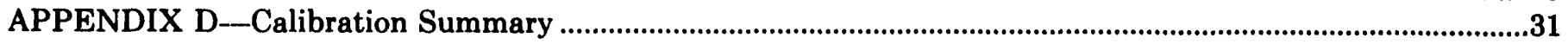

\section{Tables}

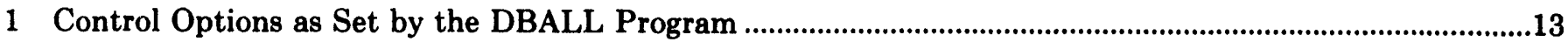

2 Control Options Adjusted for Calibration of Endevco Model 7270A-20K Accelerometer ..............................15

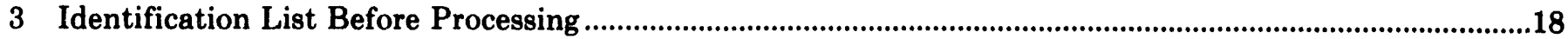

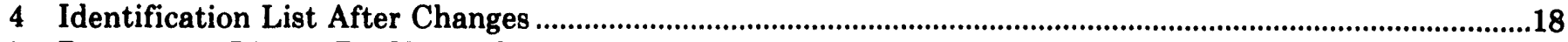

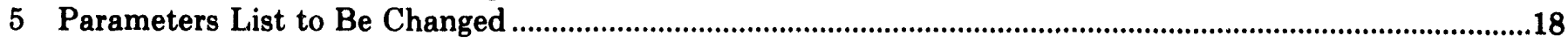

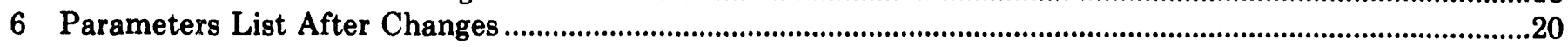




\section{Acronyms}

$\begin{array}{ll}\text { PSL } & \text { Primary Standards Lab } \\ \text { HP } & \text { Hewlett-Packard } \\ \text { PCB } & \text { Part of a company name representing "picocoulomb" } \\ \text { RMS } & \text { root-mean-square } \\ \text { CRT } & \text { cathode ray tube } \\ \text { ISA } & \text { Instrument Society of America } \\ \text { pk-pk } & \text { peak-to-peak } \\ \text { pF } & \text { picofarad } \\ \text { pC } & \text { picocoulomb } \\ \text { pC/g } & \text { picocoulomb per } g \\ \text { SSL } & \text { Sandia Standards Lab } \\ \mu V / V & \text { microvolt per volt } \\ \text { mV/N } & \text { millivolt per volt } \\ \mu V / V / V & \text { microvolt per volt per volt } \\ \text { VRMS } & \text { volt root mean square }\end{array}$




\section{Calibration of Accelerometers at the Dropball Station}

\section{Equipment Requirements}

1. Graduated Drop Tower

2. Set of Balls-Steel and Lexan

3. Set of Anvils

4. Digital Multimeter-Keithley Model 196

5. Signal Conditioning Amplifier-Vishay Model 2311

6. Amplifier-Dual Mode Kistler Model 5004

7. Amplifier-Dual Mode Kistler Model 504

8. Power Supply-Ballantine Model 2421

9. Waveform Recorder-Hewlett-Packard (HP) Model 5180A

10. Display-HP Model 1332

11. Temperature Monitor-Fluke Model 2175A

12. Calibration Capacitors-Kistler (usually 1000 and $10,000 \mathrm{pF}$ )

13. Power Unit-PCB Model 484B

14. Power Supply-HP Model 6234A (used with PCB 484B power conditioner)

15. Capacitance Meter-Doric Model 103A

16. Cabinet containing a Vacuum Pumping Station and Switches for obtaining resistance and voltage measurements.

17. Computer (HP1000), Monitor, and Printer

18. Log Book and Maintenance Manuals

The functions of the equipment listed above are described briefly in the following paragraphs. Further operational functions may be described in greater detail throughout this report.

The Dropball Station is a facility used to calibrate accelerometers by dropping a ball (usually steel) onto another ball positioned on an anvil. Reference and Test accelerometers are attached to the underside of the anvil. The dropped ball creates a shock pulse that is transmitted to the accelerometers. These shock pulses normally range between 2500 and $15,000 \mathrm{~g}$ 's, although with careful use of a tape buffer on the anvil or the light Lexan balls acceptable pulses as low as 50 g's can be generated.

\section{Graduated Drop Tower}

The mechanical apparatus of this facility consists of a 7-foot graduated tower fastened perpendiculariy onto a leveled table. Holes spaced at 2-inch intervals position a vacuum chuck that holds the ball to be dropped. A small platform permanently fastened to this tower holds a cup that catches the dropped ball.

\section{Sot of Balls}

Steel balls ranging in diameter from $3 / 4$ inch to 2 inches and Lexan balls that are 1 inch and $11 / 2$ inches in diameter are dropped on one another in some combination to initiate the shock used to calibrate an accelerometer. Heights at which balls are usually dropped vary from approximately 4 to 40 inches, although the tower is capable of holding balls as high as approximately 6 feet.

\section{Sot of Anvils}

An anvil is used to transmit a shock pulse from a ball resting upon the top end of the anvil to a reference accelerometer mounted on the botton end. The set of anvils was designed to transmit shocks of 2,500 to $12,500 \mathrm{~g}$ 's.

\section{Digital Multimotor}

A root-mean-square (RMS) voltage from the Power Supply (paragraph 3 ) is measured with a calibrated voltmeter and used to calibrate the HP5180A and HP1332 cathode ray tube (CRT) display during a SETUP before accelerometer calibrations are performed. Resistance measurements are made on semiconductor strain-gage accelerometers prior to calibration, and a DC excitation voltage from the Vishay amplifier is measured. The excitation voltage is recorded in the SETUP and used by the computer during accelerometer calibration calculations. The input and output accelerometer bridge resistances are recorded and entered into the calil ration reports. A calibrated Keithley Model 196 digital multimeter with appropriate switching is currently used as a convenient means of obtaining these measurements.

\section{5 signal Conditioning Amplifier}

A Vishay Model 2311 supplies an excitation voltage to semiconductor strain-gage type accelerometers 
under calibration. It is used to supply signals when calibrating the HP1332 and HP5180A during SETUP and to amplify and condition the signal output from the accelerometer under calibration.

\section{- Amplifier, Dual Mode (1)}

A Kistler Model 5004 dual mode amplifier is used to amplify and condition an output signal from a piezoelectric accelerometer being calibrated. It is also used during the HP1332 and HP5180A SETUP calibration for Channel B (Test Channel).

\section{Ampllfior, Dual Mlodo (2)}

Another dual mode amplifier is used to calibrate the HP1332 and the HP5180A during SETUP calibration for the Reference Accelerometer using Channel A of the HP5180A. It is used with the Reference Accelerometer throughout the culibration run.

\section{Power Supply (1)}

This power supply is used during the equipment calibration to supply voltages necessary to calibrate the HP1332 and the HP5180A.

\section{- Waveform Recorder}

An HP5180A Waveform Recorder is interfaced with the HP1000 Computer. It transmits 1024 data pairs from each (Reference and Test) accelerometer output pulse to the computer. The default acceleration corresponding to 1024 is $10,000 \mathrm{~g}$ 's. Other fullscale settings must be entered during initialization of the DBALL program.

\section{Display}

This HP1332 diplays a visual trace of the outputs from the Reference and Test accelerometers in the form of the data pairs stored by the HP5180A. Two cursors can be placed at any point of either trace on this display by adjustments from the HP5180A to read pulse voltage amplitude, record length and location, and time or frequency. This display provides an immediate visual picture of the accelerometer outputs and indicates a problem (e.g., a loose cable) when it arises. The problem can be corrected before the next drop.

\section{Temperature Monitor}

A Fluke Model 2175A is used to monitor ambient temperature at the Dropball Calibration Station. This temperature is entered on the calibration report as the accelerometer temperature during its calibration.

\section{Callibration Capacitors}

Calibrated Kistler capacitors are used in the calibration SETUP of the HP5180A and associated electronics prior to accelerometer calibration. Normally either a 1000 or a 10,000 picofarad $(\mathrm{pF})$ capacitor is used.

\section{Power Unit}

A PCB Model 484B Power Unit is used to condition the output from an Isotron accelerometer during calibration.

\section{Power Supply (2)}

An HP Model 6234A Power Supply supplies voltage to the PCB Model 484B Power Unit and is used in conjunction with it in calibrating Isotron accelerometers.

\section{Capacitanco Moter}

A Doric Model 103A Capacitance Meter calibrated by Sandia Calibration and Instrument Department, 4344, is used to measure the capacitance of piezoelectric accelerometers before calibration.

\section{Cabinet}

A relay rack cabinet houses a vacuum pump, Digital Multimeter, Dual Mode amplifiers, panelmounted connectors, power supply, and switching in a convenient arrangernent for use during calibrations.

\section{Computer}

All the data used in calibration reports are gathered an'! stored in an HP1000 Computer. An HP150 terminal, a monitor, software, and printer used with this computer monitor the data generated from tests. They then control and set the equipment functions to gather and store data from these tests and print a report from calculations based on the data.

\section{Log Book}

A $\log$ book is kept at the Dropball Calibration Station. This book includes calibration procedures and the Calibration Certificates from Sandia Primary Standards Lab (PSL) in Department 4343 on the Reference Accelerometer. It also includes the equipment history and the records and dates of equipment used.

Note: The above equipment descriptions serve only as an indication of how the equipment fits into the overall use of the Dropball Calibration Facility. Further information on individual items of equipment can be found in manuals on file in the lab.

The Dropball Comparison Calibration Station is used to shock-test accelerometers. Results from drop 
tests on a Test Accelerometer are compared to results from drop tests on a Reference Accelerometer during the same drop. The accelerometer under test is mounted "piggyback" on the Reference Accelerometer. The Reference Accelerometer normally used is an Endevco Model 2270M9 with a sensitivity of approximately 1 picocoulomb per $\mathrm{g}(\mathrm{pC} / \mathrm{g})$.

Before the calibration of each set of accelerometers, two channels of an HP5180A are calibrated. Channel $\mathbf{A}$ is calibrated as the Reference Channel in volts per $\mathrm{g}$. The volts part of this calibration is obtained from the output of the 2270M9 Reference Accelerometer. A CRT trace is used to visually monitor the calibration setup and is a visual monitor during actual tests.

Channel A (the Reference Channel) can be calibrated in three ways.

Determine a range where the Reference will give results in the same or similar order of magnitude as the accelerometers to be tested; e.g., the reference channel would be calibrated with different values for test units having a $2000 \mathrm{~g}$ limit and test units having a $20,000 \mathrm{~g}$ limit.

Method 1. Assume that the units to be calibrated are Endevco Model 2270A-2K's. The sensitivity of these accelerometers is about 7 microvolts per volt per $\mathrm{g}(\mu \mathrm{V} / \mathrm{V} / \mathrm{g})$. At the $2,000 \mathrm{~g}$ limit, the output should be about 14,000 microvolts per volt $(\mu \mathrm{V} / \mathrm{V})$ or 14 millivolts per volt $(\mathrm{mV} / \mathrm{V})$. With a 10-volt excitation voltage, output should be about $140 \mathrm{mV}$, or about 0.14 volt. Considering a sensitivity of $1 \mathrm{pC} / \mathrm{g}$ for the Reference Accelerometer, a 2,000 g shock should produce an output of $2,000 \mathrm{pC}$, and with the use of a calibrated calibration capacitor of $10,000 \mathrm{pF}$, the calibrating voltage should be $(2,000 \mathrm{pC} / 10,000 \mathrm{pF})=0.2$ volts This should be the minimum voltage considered in calibrating the Reference Channel. For ease in the calibration of this Reference Channel, let us use 0.4 volts peak-to-peak (pk-pk) with the HP5180A 2-volt range, thus assuming an approximate 4,000 pC output from the Reference Accelerometer. Calculations for this Channel A Reference setup are as follows:

$4000 \mathrm{pC} / 9996.1 \mathrm{pF}$ (the measured capacitance of the calibrated calibration capacitor) $=0.40016$ volts pk-pk $=0.14146$ volts RMS. Feed the 0.14146 VRMS through the 9996.1 pF capacitor into the REFERENCE connector to the Kistler Model 504D amplifier. This voltage is outputted to Channel A of the HP5180A. Adjust the 504D to yield a 4-volt pk-pk trace on the HP1332A monitor, using the 2-volt range on the HP5180A. If we consider the amplification in millivolts per picocoulomb, this should yield $4,000 \mathrm{mV} / 4,000 \mathrm{pC}$ $=1.0 \mathrm{mV} / \mathrm{pC}$; thus the Reference Amplifier Gain in this setup is 1.0 .

Mothod 2. Assume that accelerometers with $\mathbf{g}$ ratings for shock measurements between 2,000 and 10,000 are to be calibrated. It is usually easiest to calibrate Channel A of the HP5180A using the 5-volt range. When calibrating up to $10,000 \mathrm{~g}$ 's, use $1 \mathrm{pC} / \mathrm{g}$ for the 2270M9 Reference Accelerometer.

$10,000 \mathrm{~g}(1 \mathrm{pC} / \mathrm{g})=10,000 \mathrm{pC}$, and $10,000 \mathrm{pC} /$ $9996.1 \mathrm{pF}=1.00039$ volts $\mathrm{pk}-\mathrm{pk}=0.35364$ VRMS. As before, feed 1.00039 volts pk-pk (0.35364 VRMS) through the $9996.1 \mathrm{pF}$ capacitor into the Reference connector to the Kistler 504D amplifier, to Channel A of the HP5180A. Adjust the 504D to yield 10 volts pk-pk on the HP1332A monitor using the 5-volt range on the HP5180A. 10 velts $=10,000 \mathrm{mV}$, and again we have 10,000 $\mathrm{mV} / 10,000 \mathrm{pC}=1.0 \mathrm{mV} / \mathrm{pC}$, nd a Reference Amplifier gain of 1.0.

Mothod 3. This Reference Channel is calibrated in a similar manner for testing accelerometers capable of over $10,000 \mathrm{~g}$ shock pulses. For these accelerometers, the Reference Channel is calibrated as if $20,000 \mathrm{~g}$ 's were the maximum pulse even though normally $15,000 \mathrm{~g}$ 's is the actual maximum.

$20,000 \mathrm{~g}(1 \mathrm{pC} / \mathrm{g})=20,000 \mathrm{pC}$, and $20,000 \mathrm{pC} /$ $9996.1 \mathrm{pF}=2.00078$ volts $\mathrm{pk}-\mathrm{pk}=0.70728$ VRMS. Using this voltage and the procedure above, the Reference amplifier gain using the 5-volt range on the HP5180A is 0.5 for 10 volts pk-pk $(10,000 \mathrm{mV} / 20,000 \mathrm{pC}=? .5)$.

Reference Channel A calibration using the Endevco Model 2270M9 as the Reference Accelerometer is now complete.

\section{Piezoresistive}

\section{Accelerometer Calibration Setup}

The output from piezoresistive accelerometers under test is measured in volts, millivolts, or microvolts using Channel B of the HP5180A. The output of 
the accelerometer to be tested is used in the calibration setup of Channel B of the HP5180A.

Channel B (Test Channel) of the HP5180A can be calibrated in three ways in order to calibrate piezoresistive accelerometers:

Mothod 8 . If the accelerometer output is low, e.g., under $1 \mu \mathrm{V} / \mathrm{V} / \mathrm{g}$ for an Endevco 7270A-20K, using 10-volt excitation and a $20,000 \mathrm{~g}$ shock pulse, the output would be under a 0.2 volt peak.

$$
\begin{aligned}
& (1 \mu \mathrm{V} / \mathrm{V} / \mathrm{g})(10 \mathrm{~V})(20,000 \mathrm{~g})=(0.000010 \\
& \mathrm{V} / \mathrm{g})(20,000 \mathrm{~g})=0.2 \mathrm{~V}
\end{aligned}
$$

Feed 0.2 volt pk-pk ( 0.0707 VRMS) into the green (high) and white (low) jacks, through a Vishay Model 2311 amplifier to Channel $B$ of the HP5180A. Adjusting the 2311 amplifier to give 10 volts pk-pk on the HP1332A monitor using the 5 -volt range of the HP5180A yields a Test Gain of $50(10 \mathrm{~V} / 0.2 \mathrm{~V}=50)$.

Mothod 2. Assume that we are calibrating Endevco model 7270A-2K's with 8 sensitivity of about $7 \mu \mathrm{V} / \mathrm{V} / \mathrm{g}$. A $2,000 \mathrm{~g}$ shock pulse would yield 0.14 volt peak with 10 -volt excitation. In this case, using the 2-volt range of the HP5180A is a logical choice. Feeding 0.1 volt pk-pk into the green and white jacks as before, with the HP5180A on the 2 volt range, adjust the Vishay amplifier to yield 2 rolts pk-pk on the HP1332A monitor. Note that 4 volts would be full-screen, and with a $2,000 \mathrm{~g}$ pulse this yields a Test Gain of 20 ([4 volts full screen $/ 2 \mathrm{~J} / 0.1$ volt $=20$ ).

Mothod 3. For accelerometers that have built-in amplifiers, the output need not be fed through an external amplifier. An example is a PCB Model $305 \mathrm{M} 34$ with a sensitivity of about $80 \mu \mathrm{V} / \mathrm{g}$. Shocking this accelerometer with a $15,000 \mathrm{~g}$ shock pulse would produce an output of about 1.2 volts. When calibrating this accelerometer, $24 \mathrm{VDC}$ is supplied to it through a power conditioner (PCB Power Conditioner Model 485B) with the output to Channel B of the HP5180A. Since the largest pulse will be about 1.2 volts, the 1 -volt range $(-1.0$ to +1.0$)$ is used, yielding a Test Gain of 1.0 .
Piezoelectric Accelerometer Calibration Setup

The output from piezoelectric accelerometers is measured in picocoulombs. The sensitivity of these accelerometers is reported in picocoulombs per $\mathbf{g}$ $(\mathrm{pC} / \mathrm{g})$, and in order to calibrate the HP5180A and HP1332, a conversion of $\mathrm{pC}$ to $\mathrm{mV}$ is needed. A ratio of $1 \mathrm{mV}=1 \mathrm{pC}$ is usually used in the setup. Channel $B$ of the HP5180A is used as the Test Channel. Two examples of this setup are:

Example 1. Assume that the Test Accelerometer is an Endevco Model 2220C with a reported sensitivity of $2.9 \mathrm{pC} / \mathrm{g}$. This accelerometer is capable of handling a $5,000 \mathrm{~g}$ shock. The maximum output expected (using a sensitivity of 3.0 $\mathrm{pC} / \mathrm{g})$ is $3 \mathrm{pC} / \mathrm{g}(5000 \mathrm{~g})=15,000 \mathrm{pC}$. Using a $10,000 \mathrm{pF}$ calibration capacitor, this output is converted to $15,000 \mathrm{pC} / 10,000 \mathrm{pF}=1.5$ volts pk-pk. This 1.5 volts can be observed on the 1 -volt range $(-1.0$ to +1.0$)$ of the HP5180A. Feed 1.5 volts pk-pk through the $10,000 \mathrm{pF}$ capacitor to the Test connector, through the Kistler 5004 Amplifier to Channel B of the HP5180A. Adjust the 5004 Amplifier to yield 1.5 volts pk-pk on the monitor using the HP5180A 1 -volt range. This yields a Test Gain of $(1.5 \mathrm{~V}=1,500 \mathrm{mV})$ $1,500 \mathrm{mV} / 15,000 \mathrm{pC}=0.1 \mathrm{mV} / \mathrm{pC}$.

Example 2. Assume that the test accelerometer is a Kistler Model 8042 with a sensitivity of approximately $0.05 \mathrm{pC} / \mathrm{g}$, to be calibrated to 15,000 g's. As in Example 1, $0.05 \mathrm{pC} / \mathrm{g}(15,000 \mathrm{~g})$ $=750 \mathrm{pC}$, and $750 \mathrm{pC} / 1,000 \mathrm{pF}=0.75$ volt pk-pk.

Note: A different-value capacitor is used here to get a suitable working voltage.

Feed 0.75 volt pk-pk through a $1,000 \mathrm{pF}$ calibrated capacitor to the Test connector through the panel to Channel B of the HP5180A as above, and adjust the 5004 Amplifier to yield 7.5 volts pk-pk on the monitor with the HP5180A on the 5 -volt range. This yields a Test Gain of 7,500 $\mathrm{mV} / 750 \mathrm{pC}=10 \mathrm{mV} / \mathrm{pC}$. 


\section{Notes, Hints, and "Tricks- of-the-Trade" with the Dropball}

The following random comments reflect experience that may prove helpful in the calibrating process.

1. Adjust the Amplifiers using Input Ranges of the HP5180A (usually 5,2 , or 1 volt) according to the range that will be in actual use during a calibration run. The DBALL program automatically sets the range on both channels of the HP5180A to 5, either upon setup or by initiating another DROP-TEST sequence. Therefore, when the calibration adjustments are made, the Range should be set according to the range to be used during the test sequence and then set back to 5 (with the Range Switch and Rotary Knob) before switching automatically with the "Refer More/Less" and "Test - More/Less" function keys. This procedure will help to avoid use of the wrong scales.

2. During the setup for calibrating piezoelectric accelerometers using the Kistler 5004 Dual Mode Amplifier, switch the Operate/Reset/ Remote switch to Operate. A red light on this amplifier flashes if an overload occurs. This flashing is extinguished, and the amplifier is reset by switching to Reset and back to Operate. It is advisable to check this lamp often during calibration runs on piezoelectric accelerometers.

3. Setup calibrations on the test equipment must be performed each time a different model of accelerometer is calibrated. It is also advisable to recheck these calibrations a few times during the day.

4. Accelerometers may be screwed directly into the internally threaded end of the 2270M9 Reference Accelerometer, or they may be mounted into these threads with an adapter. Care should be taken to have these mounting surfaces clean except for a very small amount of oil that is applied to give better shock transmission. Some accelerometers, such as the Endevco Model 2225B, have a small shoulder with very little flat mounting contact. A special adapter (2983M9) was found to best transmit the shock to the 2225B.
5. Erratic results from a series of pulses may indicate a loose cable either to the 2270M9 Reference or to the accelerometer under test.

6. Pulse duration can be extended with the use of a layer or two of black electrical tape between the anvil and the ball resting on the anvil. The pulse duration can be extended further with the use of a lexan ball, by either dropping it or using it to transmit the shock pulse between the ball being dropped and the anvil. Good pulses have been obtained with the use of these lexan balls down to below 50 g's on Endevco 7270A-2K's.

7. Lead hookup for semiconductor strain gages, especially if the excitation voltage is not shut off between demounting one accelerometer and mounting another, should be in the following order: white-green-black-red. Also, the Autobalance-Reset switch should be activated each time excitation voltage is applied to an accelerometer.

8. Calibrated values for equipment used at this station may change with time. Capacitors used to calibrate the Reference and Test Channels of the HP5180A are calibrated periodically by the Electrical Standiards Lab. The values of these capacitors change a little with time, necessitating periodic changes in the calculations for test setup for both the Reference and Test Channels.

\section{Operation: Mechanical}

An Endevco Model 2270M9 accelerometer is used as a Reference Accelerometer to which accelerometers to be calibrated are compared. This 2270M9 is mounted to an anvil. Care must be taken to ensure that the mating surfaces are clean except for a bit of oil to provide good shock pulse transfer between the surfaces. An Endevco Model 30908 cable or equivalent connects the 2270M9 to the REFERENCE connector on the cabinet panel.

An accelerometer to be calibrated is inspected for burrs or evidence of misuse. Foreign material such as dental cement must be removed and the mounting holes cleaned. If the accelerometer has an attached cable, the free cable end should be clean and have wire ends long enough to work with conveniently (i.e., outer insulation should be stripped off for about $11 / 2$ in.), and the wire ends should be soldered so that they are easy to attach to binding posts that are connected to a Vishay Amplifier. The accelerometer is physically 
piggybacked onto the Endevco Reference Accelerometer. This Reference Accelerometer has a 1/4-28 NF threaded hole into which an adapter is secured. The accelerometer under test is mounted to this adapter.

The anvil, Reference Accelerometer, and accelerometer under calibration are positioned as a unit between a cup and a small spring-loaded felt-padded platform. The anvil is held in position to the underside of the platform with magnets. A ball is then placed in a small detent on the upper end of the anvil so it rests centered on the anvil. The ball that is dropped from the vacuum chuck must contact the ball resting on the anvil at a point opposite the ball-anvil contact point to assure proper shock transmission through the ball and anvil to the accelerometers.

\section{Operation: Electrical Hookup}

Different types of accelerometers are connected to Channel B of the HP5180A Waveform Recorder in different manners. Semiconductor strain gages are connected to binding posts on the small box that is connected to the Vishay amplifier. Normal ISA color code is used:

$$
\begin{aligned}
& \text { Red }=\text { positive excitation voltage } \\
& \text { Black }=\text { negative excitation voltage } \\
& \text { Green }=\text { positive output } \\
& \text { White }=\text { negative output. }
\end{aligned}
$$

If the accelerometer under test is a piezoelectric unit, the capacitance should be measured and recorded before the accelerometer is mounted to the Reference Accelerometer. Piezoelectric accelerometers are connected directly to the TEST connector on the cabinet panel by a miniature coaxial cable.

Isotrons are connected to a PCB Model 484B Power Conditioner, which is connected directly to Channel B of the HP5180A. The 484B is powered by a separate power supply.

Power is not usually applied to the connections while the accelerometer to be calibrated is being hocked up. For example, the excitation voltage power switch on the Vishay amplifier should be off during hookup of an Endevco 7270A-20K accelerometer. This allows use of the digital multimeter to obtain the accelerom icer bridge input and output resistances, which are needed to complete the information entered during report processing. After these resistances are obtained, the excitation voltage can be applied to the accelerometer by using the excitation power switch on the Vishay amplifier. This voltage is measured by using another switch on the cabinet front panel. It is inputted to the computer during setup and used during the sensitivity calculations done by the computer.

\section{Operation: Calibration Run}

The actual calibration run is accomplished by a combination of commands entered via the computer keyboard and manual tasks. After power is supplied to the equipment for a 30-minute warmup period, an accelerometer is correctly mounted, and the computer is ready with a "CI47>" prompt, the calibration run may be started.

Commands that can be entered during a calibration run by using the function keys are listed in Appendix A. This list will be referred to during the explanation of the calibration run by using the following code:

"Type" indicates a command or information that the operator enters via the keyboard, ending with a "return."

A number in brackets, e.g., [5], indicates the set of function key commands or responses available at that point. See Appendix A.

A function key, e.g., [f3], is used to enter a command or information.

A line that follows may begin with symbols like "[2] f4." This means that function key 4 is depressed while Menu [2] is current on the monitor.

The following instructions are as complete as is practical. All steps during the calibration run are explained; however, some minor details of the steps may be omitted if they are obvious and the explanation is lengthy.

With the "CI47>" prompt on the monitor, type "DBALL." This initiates the Dropball program. Software information and settings are momentarily displayed on the monitor as they are entered into the HP5180A. These entries preset the HP5180A to control options for normal conditions during a calibration. For calibration of a particular accelerometer, some of these conditions may need to be changed. This can be done during the setup for the particular accelerometer. This setup is immediately observed on the monitor after function key $f 1$ of Menu [1] is depressed. 


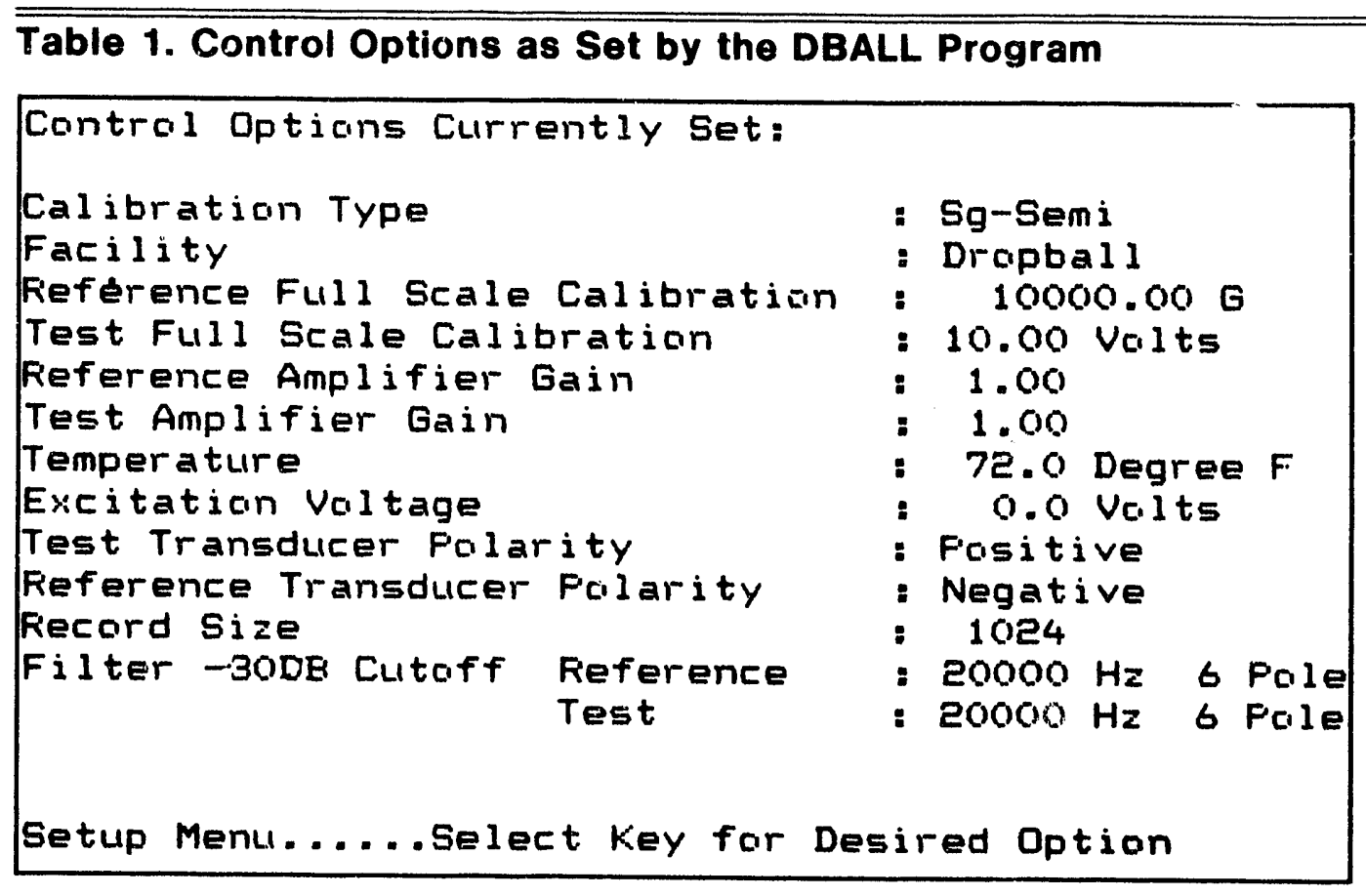

[1] f1 The Control Options that are currently set by the DBALL program appear on the monitor as in Table 1.

Because the types of accelerometers tested on this Dropball facility differ, changes usually must be made to the control options in Table 1. Some examples of such changes will be given in the following paragraphs and explained in a manner such that other changes should present no problems to the operator. Menu [2] on the monitor is essentially a listing of the control options of Table 1.

Assume that the accelerometer to be calibrated is an Endevco Model 7270A-20K. The items in the listed control options that need to be changed are "Reference Amplifier Gain," "Test Amplifier Gain," "Temperature," and "Excitation Voltage."

The Reference Full Scale Calibration and Test Full Scale Calibration listed in the Control Options of Table 1 can be changed by using $\mathrm{f} 2$ and $\mathrm{f} 3$ of Menu [2] with change s lections in Menus [4] and [5], respectively. Remember that after Channels $A$ and $B$ of the HP5180A were calibrated, they were changed back to the 5-volt range. This corresponds to the initial DBALL program setup. Then during the calibration run, the HP5180A Reference and Test ranges are changed to those corresponding to the Reference and Test amplifier gains, as explained later.

[2] f4 An "Enter Reference Transducer Amplifier Gain" request comes onto the monitor. The usual function key listing is not seen on the monitor until the reference gain is entered. The Endevco Model 2270M9 Reference Accelerometer has an acceleration shock limit of $15,000 \mathrm{~g}$ 's. The software sets the Reference Amplifier Gain (Channel A) to 1.0 for tests to $10,000 \mathrm{~g}$ 's. For tests to $15,000 \mathrm{~g}$ 's, the HP5180A is calibrated for 20,000 g's with an amplifier gain of 0.5 . Type ". 5 " on the keyboard. Similarily Test Channel B on the HP5180A is calibrated to accept an accelerometer output suitable for calibrating the $7270 \mathrm{~A}-20 \mathrm{~K}$ with approximately $0.8 \mu \mathrm{V} / \mathrm{V} / \mathrm{g}$ with Test Amplification Gain of 50.0. Refer to the first of three examples explained earlier in the section titled Piezoresistive Accelerometer Calibration Setup. An "Enter Test Transducer Amplification Gain" request appears on the monitor. Type " 50 " on the keyboard. Note that the Reference and Test amplifier gains have changed to 0.50 
and 50.00 respectively. Menu [2] appears again.

[2] f5 "Enter Excitation Voltage (Volts)" appears on the monitor. The excitation voltage was read during the electrical hookup as explained previously. Type this voltage value from the keyboard. (Assuming it was 9.9893 volts, 9.99 volts would appear in the Control Options list after "Excitation Voltage" on the monitor.) Menu [2] remains on the monitor.

[2] $\mathrm{f} 6$ The DBALL program software enters 72.0 degrees $\mathrm{F}$ for the temperature listing in the Control Options list. The ambient temperature at the Dropball facility is entered in the Calibration Report. Type the temperature as read on the Fluke Model 2175A. This temperature listing is changed and appears in the options list on the monitor. Menu [2] remains on the monitor.

[2] f7 Menu [6] appears on the monitor with a request to select the key for the desired option.

The cutoff frequencies of the digital filters can be changed at this point. Normally these are left at $20,000 \mathrm{~Hz} 6$ Pole. Occasionally a request for a different cutoff is received, and depressing $\mathrm{f} 1$ will allow requests to come onto the monitor that are easily followed to change these frequencies.

Depressing f3 will bring an "Enter Record Size $(1024,2048,4096)$ " request onto the monitor. The record size can be changed at this time but is normally left at 1024 .

[6] f2 A request "Enter Polarity of the Transducer (Positive/Negative)" appears on the monitor. Endevco accelerometers normally produce a positive output. The "Test Transducer Polarity" is entered as "Positive" in the Control Options list and does not need to be changed. The "Reference Transducer Polarity" is entered as "Negative" in the Control Options list. The Reference accelerometer used with the Dropball station is an Endevco Model 2270M9 with a positive output, but is mounted onto the anvil upside down so that the shock pulse is felt in a negative direction. The polarity then should be entered as "negative" for the Reference Transducer polarity.
A quick check to determine these polarity entries is to perform a short drop without gathering data. The HP5180A can be armed by depressing the Sample Sweep Arm switch of the Trigger Section twice and dropping a ball from a short distance (e.g. the \#1 hole on the drop tower). The Reference and Test accelerometer output traces will appear on the HP1332 display. The Positive or Negative entries in the Conirol Options list should indicate the same direction as they appear on the HP1332 display.

At this time all the required changes have been made to the Control Options to be able to collect data from shock-testing an Endevco 7270A-20K on the Dropball facility. A listing of the Control Options as changed appears on the monitor as shown in Table 2.

Referring to the HP5180A Waveform Recorder calibration for an Endevco 7270A-20K accelerometer and to the Control Options of Table 2, check the settings on the HP5180A. The "Test Full Scale Calibration" of the HP5180A and HP1332 display was calibrated for 10 volts pk-pk for 10,000 g's "Reference Full Scale Calibration" $(1 \mathrm{mV} / \mathrm{g})$. Because the Reference amplifier was adjusted for $20,000 \mathrm{~g}$ 's, the Refer ence Gain is 0.5 . The Test amplifier was adjusted with 0.2 volts pk-pk, giving a Test gain of 50.0 (10 volts/ 0.2 volts). A glance at Table 2 shows these settings.

Before continuing, check the HP5180A settings. In the INPUT Section, Channels $A$ and $B$ should both be on the 5-volt range with the "CHOP $A, B$ " indicator lit. With the TRIGGER SWEEP on "AUTO," depress the INPUT Channel A Offset switch and adjust the Channel A Reference trace on the HP1332 monitor to the center of the top grid section using the large adjustment knob. Likewise with the Channel B Offset switch adjust the Channel B Test trace to the center of the bottom grid section. Check that both "SLOPE" indicators at the bottom of the TRIGGER section are lit. The TIME BASE should indicate $1 \mu \mathrm{s}$. It is good practice to depress the following switches as a final check: CHOP A,B; Channel A Range; Channel B Range; and AUTO. This sets the HP5180A in a convenient manner to continue.

Menu [2] should still be displayed on the monitor.

[2] f8 "Main Menu-Select key for desired option" appears at the top of the monitor with Menu [1].

[1] f4 Menu [7] appears on the monitor. At this point the operation of function keys $f 5$ through $\mathrm{f} 8$ of Menu [7] will be explained before function keys $\mathrm{f} 1$ through $\mathrm{f} 4$. 


\section{Table 2. Control Options as Adjusted for Calibration of Endevco Model 7270A-20K Accelerometer.}

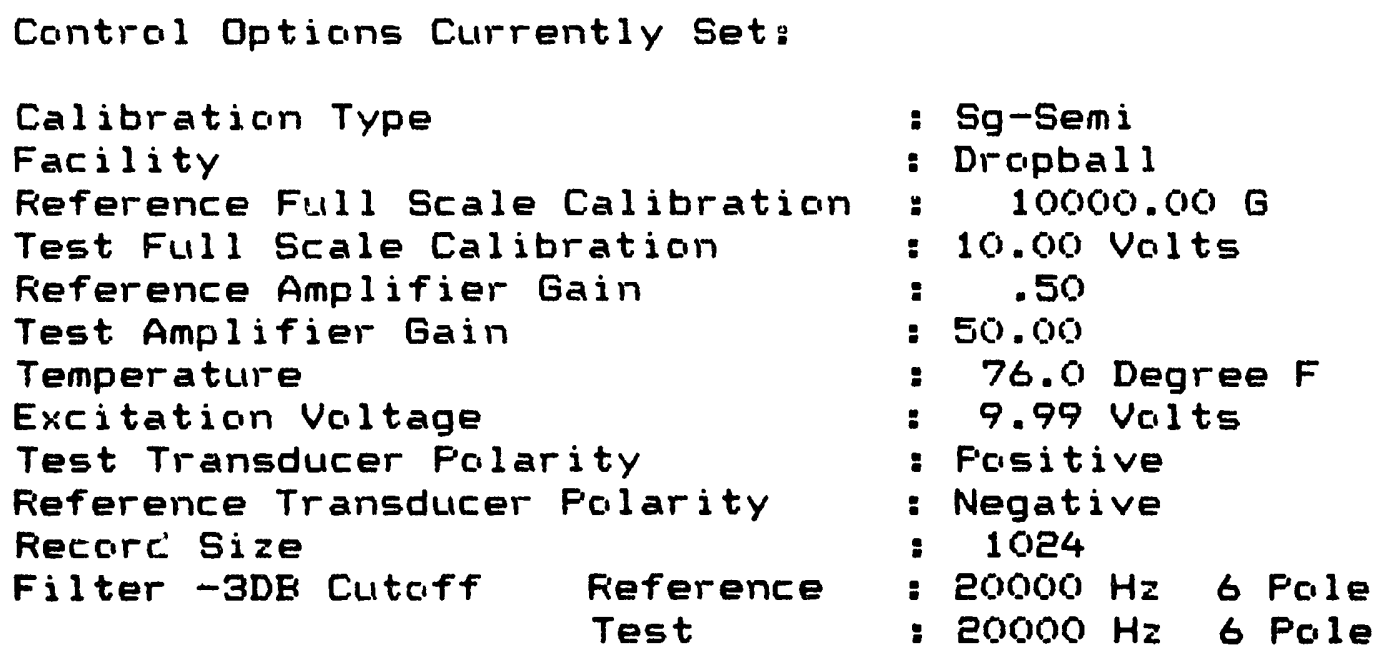

- Sg-Semi

Setup Menu......Select Key for Desired Option

Other information displayed on the monitor just above the function key listing includes Reference and Sensitivity units, and two numbers at the bottom right $(10,000.0$ and 10.0). The first number $(10,000)$ indicates the full-scale $\mathrm{g}$ value to which the HP5180A channel A (Reference Channel) has been calibrated. This number can be changed using function keys $\mathrm{f5}$ and $\mathrm{f} 6$ ("Refer More" and "Refer Less"). "Depressing f5 would increase this full-scale $g$ value for the Reference Accelerometer from 10,000 to 20,000 .

Sensitivity calculations done by the computer would be based on this increased level, resulting in a sensitivity value of approximately half of that calibrated for a $10,000 \mathrm{~g}$ full-scale Reference. To adjust this full scale back to 10,000 , depress $f 6$. Using these function keys allows this full-scale Reference $g$ value to be changed to one of five values from 20,000 to 1,000 . The value indicated on the monitor should be the same as the value used to calibrate the HP5180A Channel A (Reference Channel). The second number (10) indicates the full-scale voltage value to which Channel B (Test Channel) of the HP5180A has been calibrated. This number can be changed using function keys $f 7$ and $f 8$ ("Test More" and "Test Less"). These fullscale voltage values can be changed to one of seven test values between 20.0 and 0.2 using function keys $\mathrm{f} 5$ and $\mathrm{f} 6$. The value indicated on the monitor should be the same value as the vaiue used to calibrate the HP5180A Channel B (Test Channel).

Position a selected ball on the anvil to which the Reference and Test accelerometers are fastened, turn power on to the vacuum pump, and position a second ball to be dropped into the vacuum chuck held in position by a pin into hole number 1 approximately 4 inches above the cup. Logical first-drop conditions result for a $7270 \mathrm{~A}-20 \mathrm{~K}$ by dropping the third smallest steel ball onto the second smallest steel ball. Experience is a factor in knowing which balls to use in each test and what $\mathrm{g}$ levels are obtained from which combinations. For five data points for $7270 \mathrm{~A}-20 \mathrm{~K}$, the third smallest ball dropped on the second smallest ball from hole numbers $1,4,7,11$, and 15 give $g$ values from about 4,000 to 15,000 g's. Depress the "Single" switch in the "Trigger Sweep Arm" section on the HP5180A. All conditions should now be ready for a drop. 
[7] f1 The HP5180A shows "ARM," and "Trigger set ... Release ball within 60 seconds" appears on the monitor. The bail in the vacuum chuck is released by actuating the vacuum switch.

Menu [8] appears on the monitor with a query "Do you wish to plot data (YES/ NO)?" Depressing [8] f1 (YES) at this time will initiate graphics as seen on the HP1332 display and repeat the Reference and Test data as raw data traces with filtered data overlays on the monitor. This is done for both the reference and test accelerometers. This graphic disappears as the computer analyzes the pulse data from the shock pulse from the accelerometers, computes a sensitivity from this data, and displays it on the monitor.

[8] f2 Depressing f2 at this time eliminates the graphic displays after a drop. This is done to save time. Data from each drop is stored by the HP5180A and monitored on the HP1332 display before it is transferred to the HP1000 computer.

Two drops are needed before the software will produce a graphic display of the sensitivities corresponding to the $g$ levels of the drops. Reposition the ball in the vacuum chuck. Reposition the chuck in a different mounting hole, e.g., $\$ 4$, and reposition the ball and anvil to accept the dropped ball for the second drop. Menu [7] appears on the monitor.

[7] f1 The HP5180A display again shows "ARM," Assuming conditions are ready for the second drop, release the ball. Menu [8] appears again.

[8] f2 After the computer analyzes the data from this second drop, a graph depicting the test data as a percent deviation from full-scale reference is displayed, along with a chart containing reference, output, sensitivity, and deviation data from these two drops. Menu [7] reappears.

Repeat the above steps, repositioning the ball in the vacuum chuck at another height and the ball and anvil to accept another drop. As successive drops are made, the software will add more data to the sum- mary of $\mathbf{g}$ levels and corresponding sensitivity calculations for those $g$ levels displayed on the monitor with a graphic display of this data.

Data from a minimum of five drops are normally required for an accelerometer calibration.

Assume that a drop is made from the vacuum chuck positioned at the number 15 hole on the tower and the HP5180A did not accept the accelerometer output. Two reasons that the data may not have been accepted are:

(1) The pulse magnitude from either the Reference or Test accelerometer exceeded the magnitude of the calibrated setup of the HP5180A, or

(2) The noise level of a pulse exceeded the allowable pulse magnitude.

If either of these conditions occurs, the monitor will display Menu [8] and the following:

«*** NOTICE ${ }^{* * *}$ Scope range is inadequate

Do you wish to retain data from this pulse? (yes/no)"

Data from this drop is meaningless and is not usually saved, although one reason to save it might be to include it in a "Reject" report returned with the accelerometer to the person requesting the work. Then [8] f1 would be depressed, and the drops would be continued as in the previous steps. Assume we do not want to keep this data.

[8] f2 The data from the previous drop is deleted and Menu [7] appears. At tinis point the software changes the full-scale Reference and Test conditions originally entered in the setup. Notes to this effect appear on the monitor as follows:

"Scope Reference Xducer Full Scale Range Adjusted from: $10,000.0$ to $20,000.0$ Scope Test Xducer Full Scale Range Adjusted From: 10.0 to $20.0^{n}$

In order to have the software calculate the correct sensitivity from data from any future drops, the full-scale conditions must be brought back to those originally entered in the setup. Two adjustments must be made, and to avoid this situation again, a third adjustment can be made. To adjust the conditions back to the original, use function keys $\mathrm{f} 6$ and $\mathrm{f} 8$ of Menu [7]. 
[7] f6 The original Reference full-scale range of 10,000 reappears on the monitor and " 5 " reappears as the Channel A (Reference) range on the HP5180A. Menu [7] remains.

[7] f8 The original Test full-scale range of 10.0 reappears on the monitor, and " 5 " reappears as the Channel $B$ (Test) range on the HP5180A. Menu [7] remains on the monitor.

At this point one can assume that noise spikes exceeding the calibration levels caused the malfunction, and if another drop were made using the same conditions as existed when the unacceptable drop was made, another unwanted set of circumstances would occur as before. The noise spikes can be eliminated from the data gathered by the HP5180A by eliminating that part of the trace. This can be done by depressing the "\% MEM" switch in the Trigger Section of the HP5180A and adjusting the position reading to about $-82 \%$. This delays the pulse to a point where only the first cycle of the pulse is collected and displayed, eliminating all the noise pulses. Another drop can now be made.

Assume that a minimun of five good points for the accelerometer under calibration are collected, and one point that is definitely not on the sensitivity plot as expected. This could be caused by not repositioning the ball and anvil before a drop. This data can be eliminated by depressing the "Delete Data" function key $\mathrm{f} 2$ of Menu [7].

[7] f2 A request appears on the monitor asking which data point should be eliminated. Assuming it is data point number 3 , type " 3 " on the keyboard. Data point number 3 is deleted, and the sensitivity deviation plot with a summary of the $g$ levels and corresponding calculated sensitivities reappears on the monitor. One now has the minimum of five good data points and is ready to process the data and generate a report and label.

[7] f4 The data collection process is stopped. Menu [1] appears.

[1] f5 Menu [9] appears on the monitor with an "Identification List" to be processed into a file from which information is obtained in processing the data to generate the report and permanent file. An example of this list appears in Table 3.

Items that need to be changed in this Identification List a:e Model and Serial Number. These changes are made using the keyboard.

[9] f2 Type "7270A-20K" on the keyboard. The Model number changes in the Identification List.

[9] f3 Type "DK53F" on the keyboard, thus changing the Serial Number to DK53F.

The Identification List is now correct for this calibration. See Table 4. CAUTION: Depressing function key f7
will abort the run.

[9] f8 These items in the Identification List are saved in a temporary file until they are used in processing the report and saved in a permanent file by the HP1000 computer. Menu [17] and a list of parameters in Table 5 are displayed on the monitor.

CAUTION: Depressing function key $\mathrm{f} 7$ of Menu [17] would abort the calibration run and bring the initial "CI44" prompt back. Unless an abort is desired, do not depress $\mathrm{f} 7$.

This Parameters List must also agree with the information to be included in the Calibration Report. Items needing change are Temperature, Input Resistance, Output Resistance, Requesting Organization, and Comments.

Assume that the last accelerometer calibrated was a Kistler Model 8044, a Crystal type with a negative output. The Endevco Model 7270A-20K is a semiconductor strain gage type with a positive output. This polarity is listed in the final report and must be changed during changes in this Parameters List. Since this item does not appear in the Parameters List, it is easy to overlook. If it is not changed at this point, the report must be edited to correct it. The following three steps are used to change the polarity in the Calibration Report. They are presented here for information only since they are not needed at this particular time. 
Table 3. Identification List Before Processing.

Identification to be pracessed into file D00047::35

Manufacturer : Endevea

Model

Serial

Certified by

Calibration Type

Facility

Date/Time

: 7270A-6OK

: EM42F

: $\mathrm{FR}$

: Sg-Semi

- Dropball

: $7 / 17 / 1991 \quad 10: 49: 4$

Ta change an Identification Item.... Select Key....or Save

\section{Table 4. Identification List After Changes.}

Identification to be processed into File Do0047::35

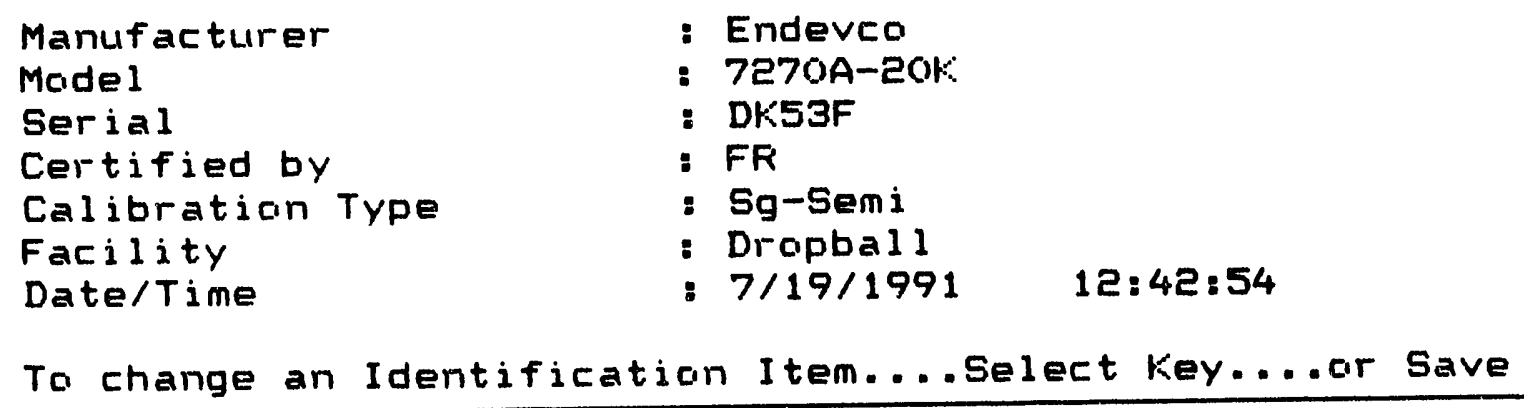

\section{Table 5. Parameters List to Be Changed.}

Farameters ta be pracessed inta File Do0047::35

Feference Input Units

Test Sensitivity Units

Temperature (Fahrenheit)

Input Fiesistance (Ohms)

Output Fiesistance (Ohms)

Insulation Fesistance (Ohms)

Analysis

Manthe valid

Fequesting Organizatian

Cummerits

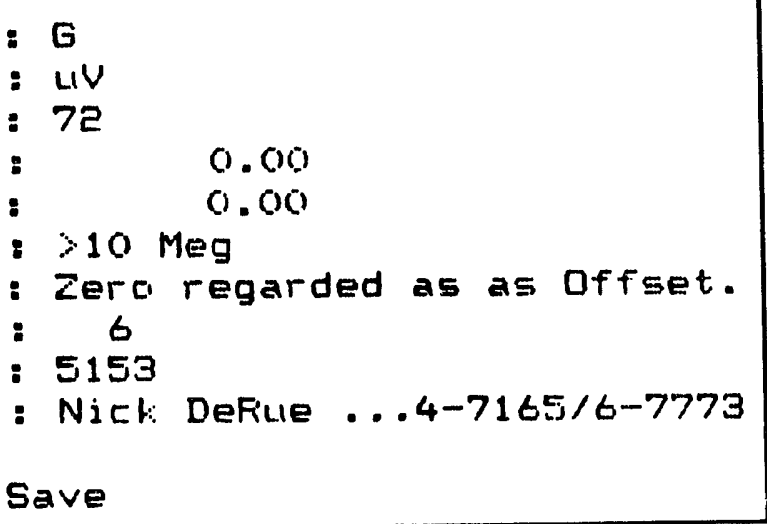

To change a parameter.. Select liey...cir Save 
[17] f6 Menu [18] appears on the monitor

[18] f5 Menu [19] appears on the monitor.

[19] f2 Menu [17] returns on the monitor with the polarity changed to "Positive".

[17] f6 Menu [18] appears on the monitor.

[18] f6 A request "Enter temperature in degree $F^{\text {" }}$ appears on the monitor. The ambient temperature at the Dropball facility is typed from the keyboard. In this case the temperature was 77 degrees. The Parameters List appears with the temperature changed. Menu [17] appears.

[17] f1 A request "Enter input bridge resistance (Ohms)" appears on the monitor. Type the input resistance as recorded before the calibration run was begun. A second request "Enter output bridge resistance (Ohms)" appears on the monitor. Type the output resistance as recorded before the run was begun. The Parameters List appears on the monitor with the Input and Output resistances changed. Menu [17] appears on the monitor.

[17] f2 A request "Enter the requesting organization (12 characters maximum)" appears on the monitor. Type the organization number from the keyboard. Note that the "Requesting Organization Number" has changed. Menu [17] remains.

[17] f4 The computer program and space on the report allow for three lines of comments, which are typed from the keyboard. The first two lines can be a maximum of 48 characters each, and the third line can be a maximum of 24 characters. The comments are typed, after which the Parameters List should agree with the information to be included in the Calibration Report. Compare Table 6 with Table 5 for these information changes.

[17] f8 The information in the Parameters List is stored in a temporary file in the computer buffers. Menu [21] appears on the monitor.

[21] f1 The data collected by the HP5180A is processed by the HP1000 computer, and a report is automatically printed. See Appendix B. After the report is printed, the question "Do you wish to retain a permanent data file (yes/no)?" and Menu [22] appears on the monitor.

[22] f1 Data as printed in this report is transferred to a permanent file. At this point if [22] $\mathrm{f} 2$ were depressed, the data from this calibration run would not be saved in a permanent file, and Menu [1] would appear on the monitor. If a permanent file is desired even if the accelerometer is to be rejected, depress [22] f8. Data is then transferred to a permanent file with "REJECT" in place of the temperature, which would be indicated upon withdrawing this report from the permanent files. A request "Do you wish to make a label (yes/no)?” with Menu [8] appears on the monitor.

[ 8] f1 A label is generated and printed by the computer. See Appendix C. Menu [23] appears on the monitor with a request "Do you wish a history summary (no/softcopy/ hardcopy)?"

[23] f3 No history summary appears if $\mathrm{f} 1$ is depressed. The history summary appears on the monitor if $\mathrm{f} 2$ is depressed. A hardcopy is printed if $\mathrm{f} 3$ is depressed. This history of an accelerometer includes a record of pertinent information regarding the calibrations on that accelerometer. See Appendix D. Menu [1] appears on the monitor.

The calibration on this accelerometer is complete. Another accelerometer of the same model can be mounted and calibrated using the same procedures as above after depressing $\mathrm{f} 4$ (with Menu [1]). If a different model accelerometer is to be calibrated, depress $\mathrm{f} 1$ (Setup) and continue as described above. If no more calibrations are to be made, depress $\mathrm{f} 8$ (Exit). The "CI47>" prompt will appear on the monitor, and the equipment may be shut down. 
Table 6. Parameters List After Changes.

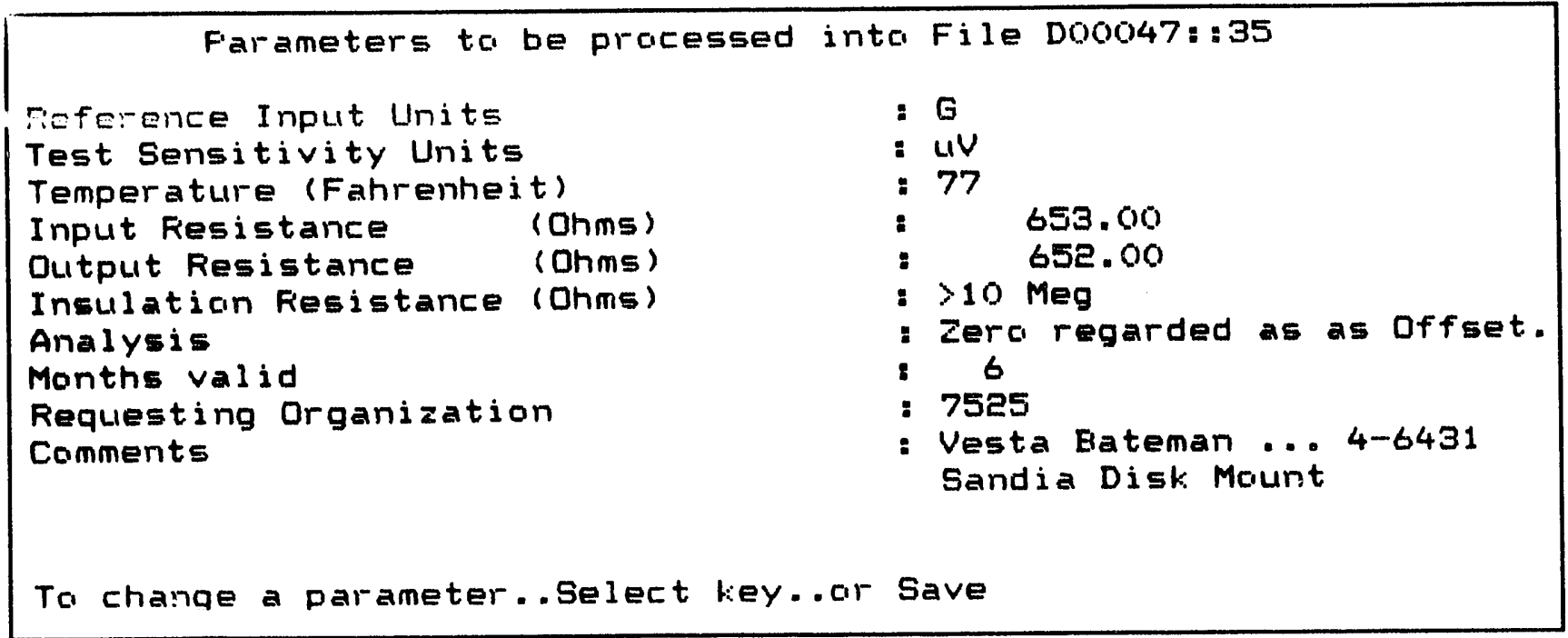

\section{System Uncertainty}

The Endevco Model 2270M9 reference accelerometer is calibrated against a Kistler Model $805 \mathrm{~A}$ transfer standard that has been shock-calibrated by the PSL. The uncertainty assigned by the PSL is $8 \%$. The primary readout device, the HP5180A Waveform Recorder, is calibrated at the time of use by applying a measured $\mathrm{AC}$ voltage through a measured capacitor into a charge amplifier, the output of which goes to the HP5180A. The amplifier gain is adjusted until the waveform recorder reads the desired volts for the quantity of charge input. Uncertainties for the capacitor and voltmeter are given by the Sandia Standards Lab as $0.5 \%$ and $0.3 \%$ respectively. Repeatability for the HP5180A is estimated as $1 \%$.

Using the Root-Sum-of-Squares combination, the system uncertainty becomes:

$$
\begin{aligned}
& \mathrm{UNC}=\left[8^{2}+2 \times\left(0.5^{2}+0.3^{2}+1^{2}\right)\right]^{0.5}=8.2 \% \\
& \text { (of reading) }
\end{aligned}
$$

The capacitor, voltmeter, and HP5180A components are multiplied by two since the same setup is used to transfer from the Kistler $805 \mathrm{~A}$ to the reference $2270 \mathrm{M} 9$.

\section{Acceptance Specifications}

Each accelerometer is accepted or rejected depending on performance during the calibration run. It may be rejected during preliminary checks prior to the calibration run for physical damage or for electrical failure, i.e., opens or shorts, or high or low resistance reading instead of normal for that particular accelerometer. It may be rejected after the run, depending on the comparison between prior and current results, or for poor uncertainty. Results from the current run must be within the following tolerances, or the unit is rejected. All comparisons are to the current run.

(a) previous run on dropball .............................8\%

(b) previous run on shaker ..............................8\%

(c) previous run on centrifuge .......................10\% 


\section{Calibration Requirements}

The requirements for instrument calibration for this laboratory and in particular for instruments calibrated with this Dropball Facility are included in condensed forms of volumes of Sandia Laboratories specifications. Two publications that pinpoint the pertinent parts of these specifications are:

(1) Memorandum of Record Regarding Calibration Requirements; by W. B. Leisher, 7545, and P. L. Walter, 7545, dated December 16, 1986.

(2) Calibration Requirements, Division 7545 Calibration Station; by P. L. Walter, 7545, W. B. Leisher, 7545, and R. L. Crabb, 7243; dated February 20, 1986.

\section{Safe Operating} Procedures

This Dropball Calibration Station is but one calibration facility in Bldg 828. Safe Operating Procedures for the use of this facility are included in SP472159, "Activity Specific ES\&H Standard Operating Procedures, Shock Accelerometer Calibration System, Building 828," approved by T. J. Young, 2410, 1/15/92. 


\section{APPENDIX A \\ Function Key Listing (Menus)}


Function Key Listing (Menus)

\begin{tabular}{|c|c|c|c|c|c|c|c|c|}
\hline & $f 1$ & $f 2$ & f3 & $f 4$ & f5 & fo & f7 & $f 8$ \\
\hline$[1]$ & SETUF' & & & $\begin{array}{l}\text { DROF- } \\
\text { TEST: }\end{array}$ & $\begin{array}{c}\text { PROCEESS- } \\
\text { DATA }\end{array}$ & & & $\bar{E} \bar{X} \bar{I} \bar{T}^{--}$ \\
\hline$[2]$ & $\begin{array}{l}\text { CAL } \\
\text { TYPE }\end{array}$ & $\begin{array}{l}\text { REFEF'- } \\
\text { SENS }\end{array}$ & $\begin{array}{l}\text { TEST' } \\
\text { SENSS }\end{array}$ & 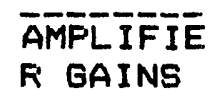 & $\begin{array}{l}\text { EXXITE } \\
\text { VOLTS }\end{array}$ & $\begin{array}{l}\text { TEMPP } \\
\text { DEERREE F }\end{array}$ & DTTHER & $\overline{C O N} \bar{T} \bar{I} \bar{N} \overline{U^{\prime}}$ \\
\hline$[3]$ & CRYSTAL & - & $\overline{C O N \bar{T}}=\overline{A M} \bar{F}$ & $\overline{S Y} \bar{S}=\overline{A M P}-$ & $\overline{M E} \overline{T A L} \overline{\bar{S}} \bar{G}$ & $\overline{S G} \overline{S E M M I}$ & & \\
\hline$[4]$ & -20.000 & $-10,000$ & $4000^{--}$ & $2000^{--}$ & $1000^{--}$ & $400^{-}$ & $200^{-1}$ & 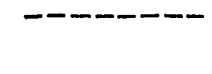 \\
\hline [5] & $20.0^{--}$ & $10.0^{--}$ & $4.0^{--}$ & $-5.0^{--}$ & 1.0 & -0.4 & $0.2^{-\cdots}$ & 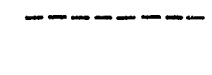 \\
\hline$[6]$ & $\begin{array}{l}\text { DIJGITAL } \\
\text { FILTER }\end{array}$ & $\bar{F} \overline{O L A} \bar{A} \bar{I} \bar{I} \bar{Y}$ & $\begin{array}{l}\text { RECORD- } \\
\text { SIZE }\end{array}$ & $\ldots$ & -1 & 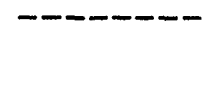 & -- & COONTTINUE \\
\hline$[7]$ & $\begin{array}{l}\text { ARM } \\
\text { TRIIGGER }\end{array}$ & $\begin{array}{l}\text { DELETEE } \\
\text { DATA }\end{array}$ & & $\begin{array}{l}\text { STOF' } \\
\text { DROF'S }\end{array}$ & $\begin{array}{l}\text { REFEF- } \\
\text { MORE }\end{array}$ & $\begin{array}{l}\text { REFER- } \\
\text { LESS }\end{array}$ & $\begin{array}{l}\text { TEST } \\
\text { MOFEE }\end{array}$ & $\begin{array}{l}\text { TEST'- } \\
\text { LESS }\end{array}$ \\
\hline$[8]$ & YESE & $\bar{N} \bar{O}^{-}$ & & $\ldots$ & & & & \\
\hline$[9]$ & $\overline{M F} \bar{G}^{-}$ & MODEEL & SEFF' & $\overline{C A L}=\overline{E Y}$ & $\overline{C A} \bar{A}=\overline{T Y P} \bar{P}$ & $\bar{F} \bar{A} \bar{C} \bar{I} \bar{I} \bar{I} \bar{Y} \bar{Y}$ & $\overline{A B D E T}$ & SAVUE \\
\hline$[10]$ & $\bar{E} \bar{N} \overline{D E} \overline{\mathrm{V}} \bar{C} \bar{C}^{-}$ & RISTALEF́ & KULITE & $\cdots$ & ENTEANA & $\overline{N O} \bar{R} \bar{W} \bar{O}$ & PCE & OTHEF \\
\hline [111] & $\overline{S T A} \bar{A} \overline{T H} \overline{A M}$ & NŌĒWŌODD & ELE & $\overline{V A} \bar{A} \bar{I} \overline{D Y N} \overline{N E}$ & $\bar{C} \bar{L} \bar{L} \bar{E} \bar{S} \bar{C} \overline{-}$ & & & \\
\hline$[12]$ & WINLE & SANCAHE & FEE $\bar{A} \bar{A} \bar{C} \overline{C H K}$ & $\overline{P E} \bar{C} \overline{C H A T}-$ & HAREAOUR & EROWN & & \\
\hline
\end{tabular}




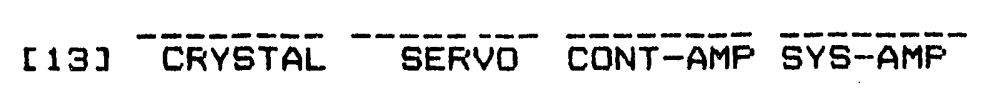

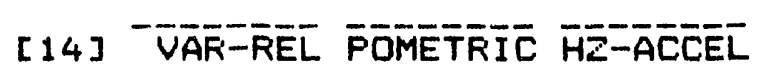

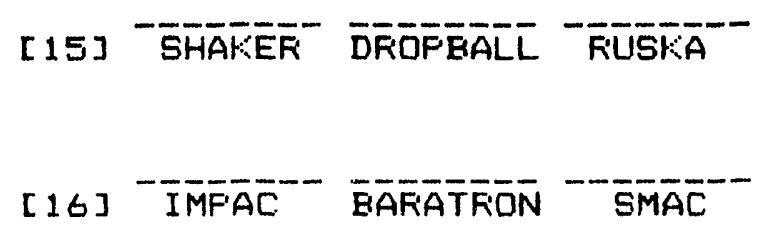
[17] $\begin{gathered}\text { EFIDGE } \\ \text { OHMS REEUEST }\end{gathered}$
ORGN SUFF'TY COMMENTS
EXCITE

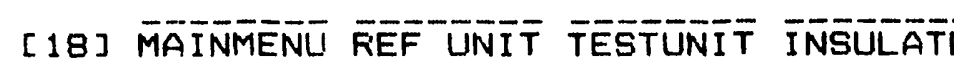

[19] N̄EGATTIVE F'DSTTIVE

$\bar{C} \bar{F} \bar{U} \overline{G E} \overline{-1} \bar{Y}$
$[20]$

$-$

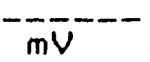

政

$u \bar{v}$<smiles></smiles>

VDLTT

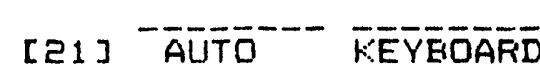

[2อ]

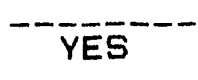

$-\overline{N O}$

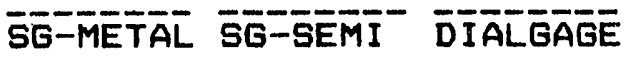

QTTHEF'

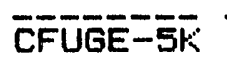

KING

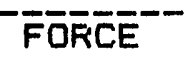

QTTHER

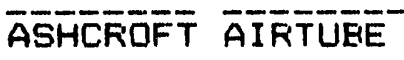

CFIYSTÁLpfd

- $\overline{\text { TTHER }}$

- $\bar{A} \bar{E} \bar{B} \overline{R T}$

$\overline{S A V E}$

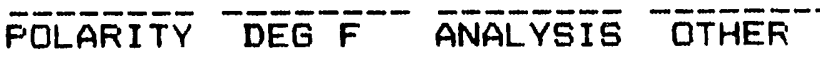

HEFTTE- FEEADING 


\section{APPENDIX B}

\section{Transducer Calibration Report}




\section{TRANSDUCER CALIBRATION REPORT}

SANDIA LABS $2414 \quad 7 / 19 / 1991$

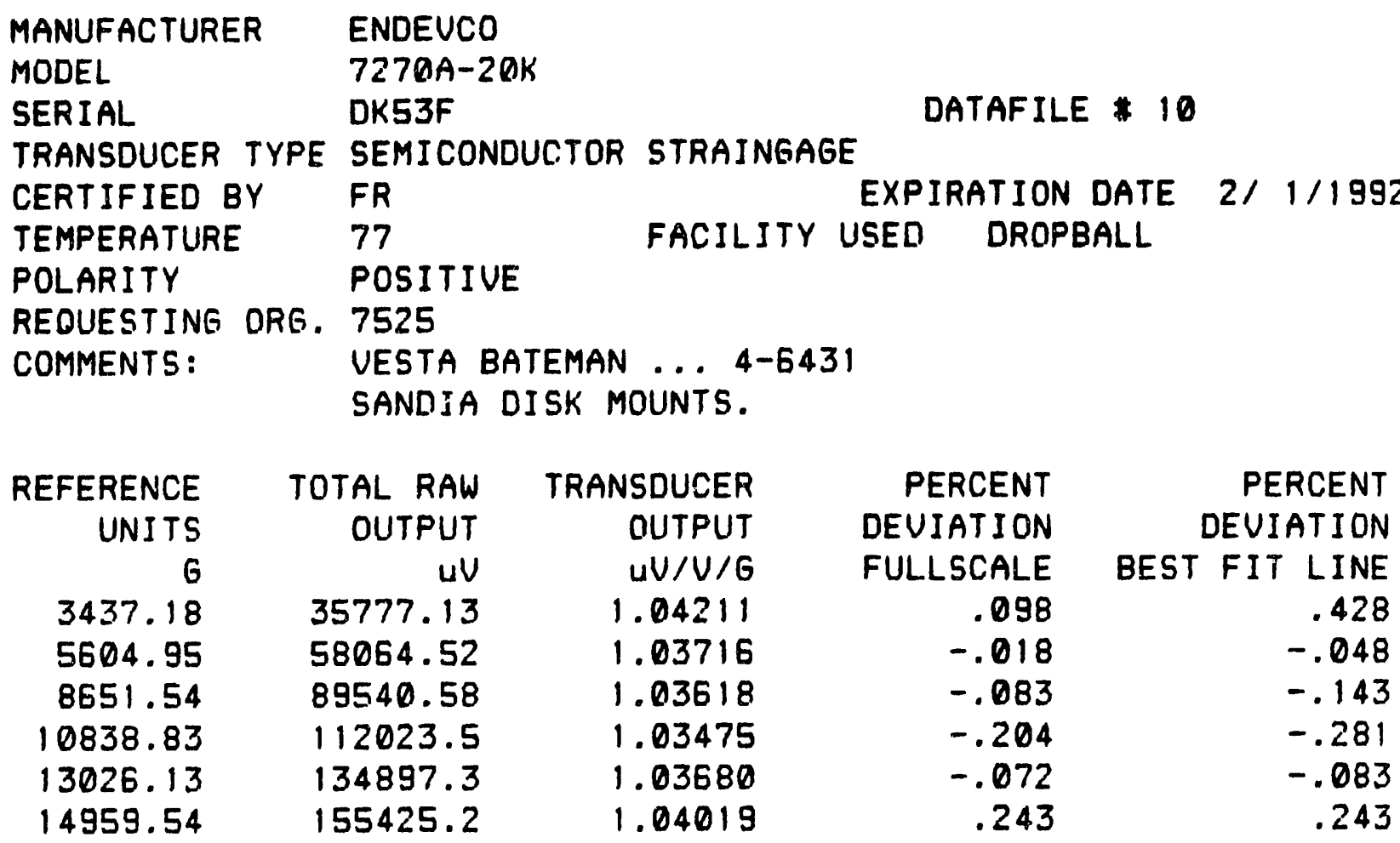

SENSITIVITY $=.1038 E+01 \quad U V / U / G$

BEST FIT STRAIGHT LINE SENSITIUITY EQUATIONS:

$G=(.9637 E+00 *$ UV )/EXCITATION VOLTAGE

$u V=(.1038 E+01 * G \quad) *$ EXCITATION VOLTAGE

RESISTANCE (OHMS) INPUT $=653.0$ OUTPUT $=652.0 \quad$ INSULATION $=>10 M E G$

TEST EXCITATION 10.0 VOLT

ZERO: $\quad 0.00000$ UV TREATED AS OFFSET

PERCENT DEYIATIDN FROM FIJLL SCALE REFERENCE

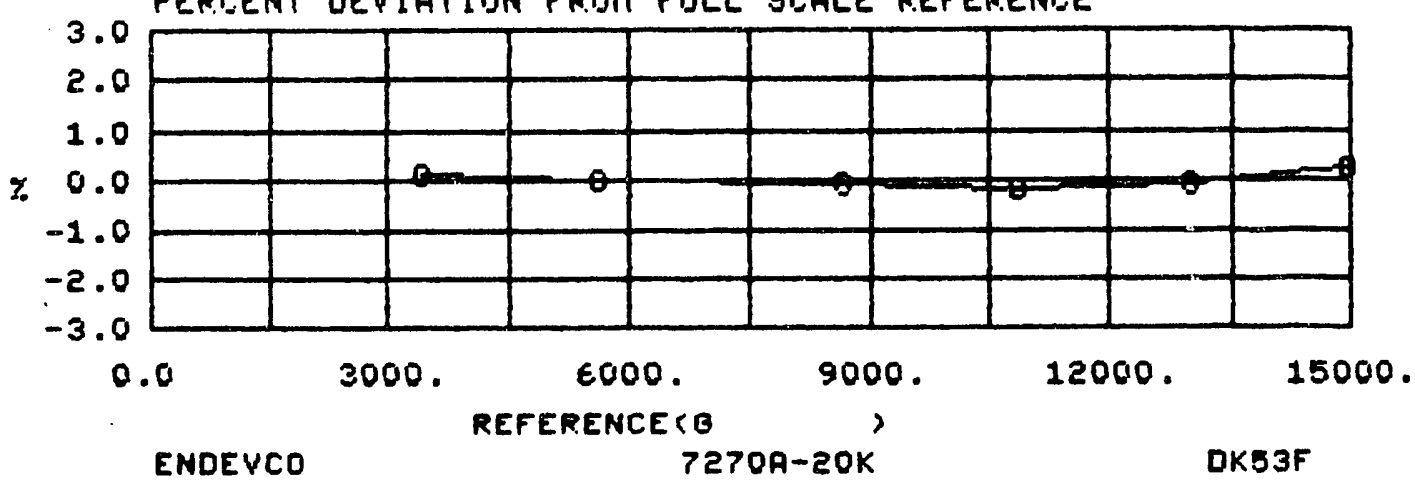




\section{APPENDIX C}

Transducer Label 


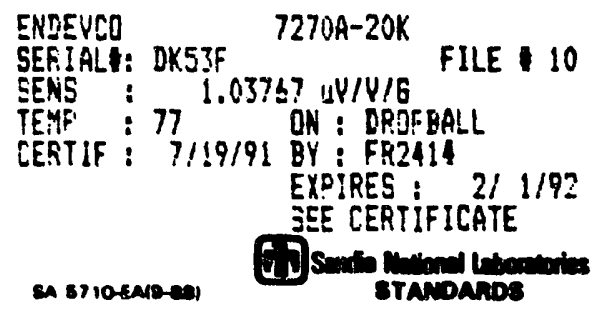




\section{APPENDIX D \\ Calibration Summary}


CALIBRATION SUMMARY

$\begin{array}{ll}\text { MANUFACTURER } & : \text { ENDEUCO } \\ \text { MOOEL } & : 7270 A-20 K \\ \text { SERIAL } & : \text { DK53F }\end{array}$

FILE DATE SENSITIUITY INPUT OUTPUT $\&$ XCITE FACILITY CAL-TYPE DEGREE WV IU/G OHMS OHMS CHANGEVOLTS $F$

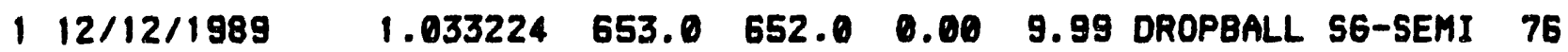

$212 / 14 / 1989 \quad 1.069930653 .0 \quad 652.0 \quad 3.43 \quad 9.98$ SHAKER S6-SEMI AMBIENT

$\begin{array}{llllllll}3 & 21 & 2 / 1990 & 1.033628 & 652.0 & 651.0 & 3.51 & 9.99 \\ & \text { DROPBALL S6-SEMI } 72\end{array}$

$48 / 9 / 1990 \quad 1.061690 \quad 652.0 \quad 652.0 \quad 2.64 \quad 9.99$ DROPBALL S6-SEMI 82

$58 / 13 / 1990 \quad 1.071293652 .0 \quad 652.0 \quad .90 \quad 9.98$ SHAKER S6-5EMI AMBIENT

$68 / 31 / 1990 \quad 1.044391651 .0 \quad 651.0 \quad 2.58 \quad 9.99$ DROPBALL S6-SEMI 82

$\begin{array}{lllllll}7 & 8 / 31 / 1990 \quad 1.065336 & 651.0 & 651.0 & 1.97 & 9.98 & \text { SHAKER S6-SEMI AMBIENT }\end{array}$

\begin{tabular}{lllllll}
8 & $10 / 16 / 1990$ & 1.055565 & 653.0 & 653.0 & .93 & 9.99 \\
\hline
\end{tabular}

$910 / 22 / 1990 \quad 1.069890653 .0 \quad 653.0 \quad 1.34 \quad 9.98$ SHAKER S6-SEMI AMPTENT

$10 \quad 7 / 19 / 1991 \quad 1.037667 \quad 653.0 \quad 652.0 \quad 3.11 \quad 9.99$ DROPBALL S6-SEMI 77 


\section{DISTRIBUTION:}

$\begin{array}{rll}1 & 2664 & \text { David E. Ryerson } \\ 1 & 2706 & \text { M. W. Sterk } \\ 1 & 2741 & \text { T. J. Baca } \\ 1 & 2741 & \text { D. O. Smallwood } \\ 1 & 2757 & \text { P. Walter } \\ 1 & 4301 & \text { D. N. Bray } \\ 1 & 4307 & \text { R. T. Johnson } \\ 1 & 4341 & \text { L. J. Azevedo } \\ 1 & 4341 & \text { R. R. Romero } \\ 1 & 4344 & \text { J. M. Simons } \\ 1 & 4344 & \text { D. A. Sanchez } \\ 1 & 4344 & \text { S. A. Harbour } \\ 1 & 4344 & \text { C. J. Pelchat } \\ 10 & 4344 & \text { F. N. Rebarchik } \\ 1 & 4344 & \text { W. F. Windle } \\ 1 & 6643 & \text { W. B. Leisher } \\ 1 & 6643 & \text { T. L. Sanders } \\ 1 & 8275 & \text { D. P. Van Dyke } \\ 1 & 9142 & \text { R. D. Robinett } \\ 1 & 8523-2 & \text { Central Technical Files } \\ 5 & 7141 & \text { Technical Library } \\ 1 & 7151 & \text { Technical Publications } \\ 10 & 7613 & \text { Document Processing } \\ & & \text { For DOE/OSTI } \\ & & \end{array}$



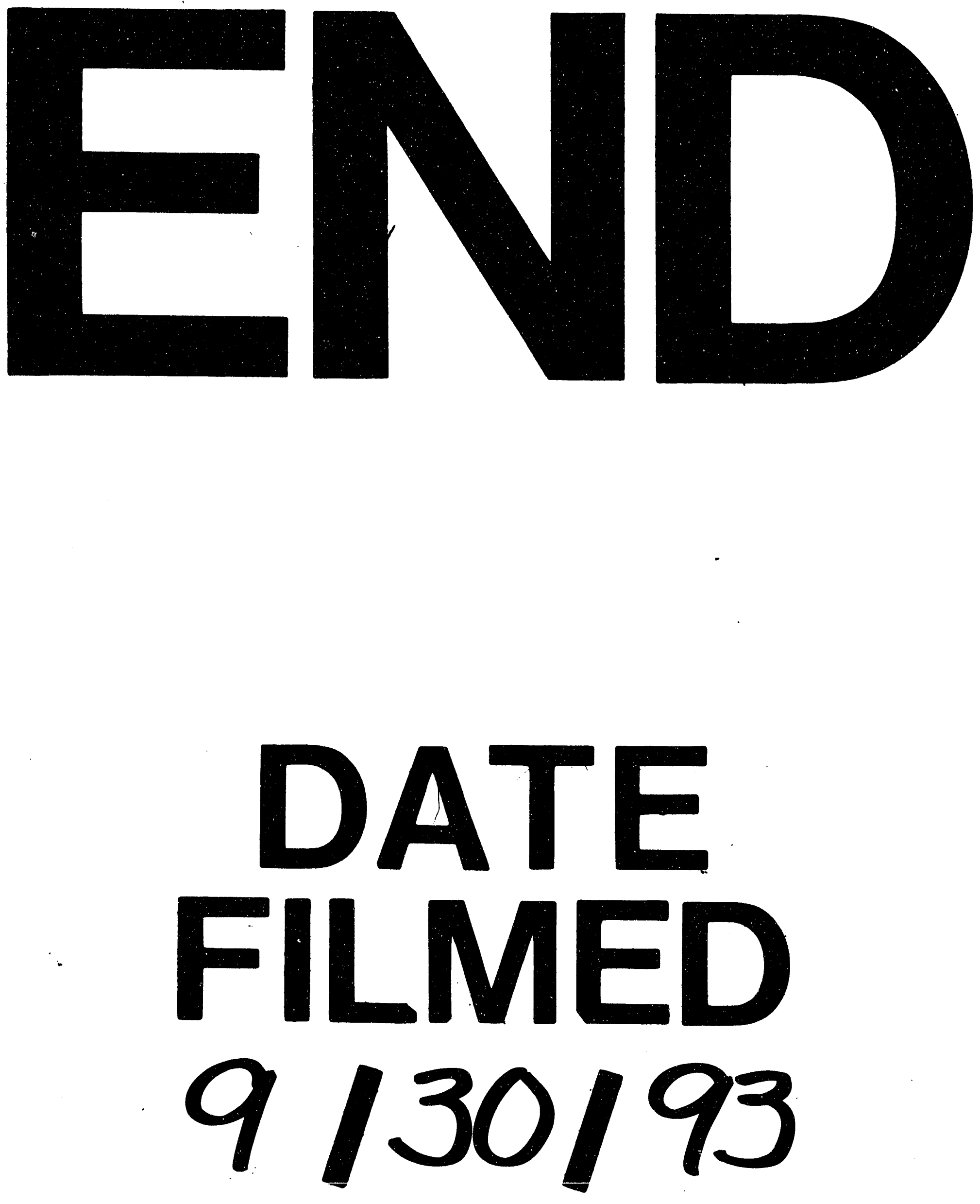
